\title{
Comunidade infestante sob duas condições de irrigação na cultura do arroz de sequeiro
}

\section{Weeds under two conditions of irrigation in culture of the upland rice}

\author{
Thiago Gledson Rios Terra ${ }^{1}$, Tarcísio Castro Alves de Barros Leal ${ }^{2 *}$, Thomas Vieira \\ Nunes $^{2}$, Eduardo Andrea Lemus Erasmo ${ }^{2}$, Tarliane Martins Tavares ${ }^{3}$ e Dione Pereira \\ Cardoso $^{2}$
}

${ }^{1}$ Universidade Federal de Viçosa; 36571-000; Viçosa - MG - Brasil; ${ }^{2}$ Universidade Federal do Tocantins; 77402090; Gurupi - TO - Brasil; ${ }^{3}$ Universidade Federal do Ceará; 60020-181; Fortaleza-CE - Brasil.

\begin{abstract}
The objective of the work was to evaluate the weeds and dry mass in the culture of the upland rice, under two conditions of irrigation (with and without it dry stress). The experiment was installed in the Experimental Station of the Campus of Gurupi-TO, belonging to the Federal University of Tocantins (UFT). The survey of the weeds was made to the end of the reproductive cycle of the rice plants, by the sampling method, being the same ones, collected to evaluate the dry mass. Among weed families found in the experiment, it was evidenced occurrence of lesser number ( 8 families) in area with dry stress in relation to the area without stress ( 9 families). The number of joined species was the same (13 species) in both areas, having variation, according to the culture environment. The species that more detached had been would type Digitariahorizontalis and Emilia sonchifolia for both conditions. The weeds, in the condition of dry stress, tended to present minor dry mass when comparer to those under condition without it stress for water deficiency.
\end{abstract}

Key-words: Dry stress, weeds, dry mass, Oryza sativa L

\section{INTRODUÇÃO}

Áreas cultivadas em geral, apresentam condições favoráveis para o surgimento de espécies de plantas espontâneas denominadas "plantas daninhas". Essas competem com as plantas cultivadas pelos mesmos fatores de sobrevivência, tais como luz, nutrientes, espaço e água, acarretando diminuição da produtividade (Paulo et al., 1990) e perdas na qualidade dos grãos. Dependendo de diversos fatores, tais como nutrientes, luminosidade, espaço e umidade do solo, algumas espécies daninhas podem se expressar com maior ou menor vigor $\mathrm{e}$ intensidade.

$\mathrm{O}$ arroz de terras altas é cultivado em terras firmes onde os índices pluviométricos, as enchentes dos rios e o afloramento natural dos lençóis freáticos são as fontes de água disponíveis para o desenvolvimento das plantas (Silva et al., 2011), e portanto, vulnerável ao estresse de seca. Esse tipo de estresse tem efeito em diversos processos bioquímicos, fisiológicos e morfológicos nas plantas, visto geralmente aumentar a resistência difusiva ao vapor de água, mediante o fechamento dos estômatos. Tal fato reduz a transpiração, o suprimento de dióxido de carbono para o processo fotossintético, o crescimento celular e induz o aumento da fotorrespiração (Shinozaki e Yamaguchi-Shinozaki, 2007; Taiz e Zeiger, 2009). A sobrevivência depende, principalmente, da velocidade de resposta aos acúmulos externos (Vidal et al., 2005).

De acordo com Bota et al. (2004), o estresse de seca induz a efeitos deletérios sobre o vigor e altura em plantas de arroz, podendo com isso, apresentar menor capacidade competitiva em relação às plantas daninhas. Para Nguyen et al. (1997), os mecanismos fisiológicos de tolerância à

$\overline{\text { *Author for correspondence: tarcisio@uft.edu.br }}$ 
seca estão relacionados ao uso moderado da água pela planta, redução da área foliar, controle da perda de água pelas folhas e habilidade das raízes em explorar camadas mais profundas do solo.

A eficiência do uso da água é caracterizada como a quantidade de água evapotranspirada por uma cultura para a produção de certa quantidade de matéria seca, sendo assim, culturas mais eficientes no uso da água produz mais matéria seca por grama de água transpirada (Concenço et al., 2007). De acordo com Procópio et al. (2004) existem plantas daninhas que possuem maior eficiência no uso da água que determinadas plantas cultivadas, aumentando assim a competitividade dessas em relação às culturas.

A tomada de decisão das estratégias de controle das plantas daninhas pode basear-se no balanço competitivo entre a comunidade infestante e a cultura agrícola. O balanço competitivo é dependente de fatores ligados à própria comunidade infestante, como composição e densidade florística emergente, e também a fatores ligados à cultura, como espécie ou variedade, espaçamento e densidade de plantio (Erasmo et al., 2003).

Nesse trabalho, objetivou-se avaliar a composição, densidade florística e fitomassa seca da comunidade infestante na cultura do arroz de terras altas, sob condições normais de irrigação e sob estresse de seca.

\section{MATERIAL E MÉTODOS}

O experimento foi conduzido na estação experimental do Campus Universitário de Gurupi TO, pertencente à Universidade Federal do Tocantins (UFT), localizado a $11^{\circ} 43^{\prime} 45^{\prime \prime} \mathrm{S}$ e $49^{\circ} 04^{\prime} 07^{\prime \prime} \mathrm{W}$ e a $280 \mathrm{~m}$ de altitude. Caracteriza-se, climaticamente, por temperatura média anual em torno de $26^{\circ} \mathrm{C}$, umidade relativa do ar de $68,5 \%$ e precipitação média anual em torno de $1400 \mathrm{~mm}$ (Seagro, 2007).

O solo do local é caracterizado como Latossolo Amarelo distrófico, com textura arenosa. A fertilidade do solo, de acordo com a análise, apresentou-se baixa (Tabela 1), havendo, na ocasião do plantio, a necessidade de utilizar adubação suplementar. A adubação de plantio foi feita utilizando-se NPK mais $\mathrm{Zn}$, nas proporções de $12,90,48$ e $20 \mathrm{~kg} \mathrm{ha}^{-1}$ de $\mathrm{N}, \mathrm{P}_{2} \mathrm{O}_{5}, \mathrm{~K}_{2} \mathrm{O}$ e sulfato de zinco, respectivamente. A adubação de cobertura foi realizada a lanço aos vinte e cinco dias após a emergência (DAE) das plantas de arroz, aplicando-se $45 \mathrm{~kg} \mathrm{ha}^{-1}$ de $\mathrm{N}$ na forma de uréia.

Tabela 1. Resultados da análise de solo da área experimental realizada em março de 2008.

\begin{tabular}{|c|c|c|c|c|c|c|c|c|c|c|c|}
\hline \multicolumn{12}{|c|}{ Análise de solo } \\
\hline \multicolumn{5}{|c|}{ cmol dm ${ }^{-3}$} & \multicolumn{2}{|c|}{$\mathrm{mg} \mathrm{dm}^{-3}(\mathrm{ppm})$} & \multirow{2}{*}{$\frac{(\%)}{\text { Mat.Org. }}$} & \multirow{2}{*}{$\frac{\mathrm{pH}}{\mathrm{H}_{2} \mathrm{O}}$} & \multicolumn{3}{|c|}{ Textura $\left(\mathrm{g} \mathrm{kg}^{-1}\right)$} \\
\hline $\mathbf{C a}$ & Mg & Al & $\mathbf{H}+\mathbf{A l}$ & $\mathbf{K}$ & $\mathbf{K}$ & $\mathbf{P}(\mathrm{mel})$ & & & Areia & Silte & Argila \\
\hline 1,65 & 0,47 & 0,09 & 3,23 & 0,06 & 21,5 & 0,6 & 3,0 & 5,6 & 562,5 & 127,5 & 310 \\
\hline
\end{tabular}

A área experimental foi cultivada no ano anterior (2007), na época da estação seca, com a cultura do arroz de terras altas. Posteriormente, na estação chuvosa, foi semeada Crotalaria juncea (2007/2008), para adubação verde, com média de $40 \mathrm{~kg}$ de sementes ha ${ }^{-1}$.

A semeadura do arroz de terras altas do ano de 2008 foi realizadano dia 08 de maio, correspondendo ao início da estação seca,em sistema de plantio convencional, com uma gradagem pesada e duas leves ou niveladoras. O espaçamento entre linhas foi de $0,25 \mathrm{~m}$ com média de 80 sementes por metro linear, totalizando a área de 0,50ha, dividida em duas partes, com e sem deficit hídrico.

Foi aplicado em pré-emergência, por intermédio de pulverizador tratorizado de barras equipado com bicos tipo cone, cuja vazão correspondeu a $3001 \mathrm{ha}^{-1}$, o herbicida oxadiazon, na proporção de $1000 \mathrm{~g}$ do ingrediente ativo por ha.

A área experimental foi irrigada sem distinção entre os tratamentos até os $30 \mathrm{DAE}$, utilizando-se sistema de irrigação formado por conjunto autopropelido e carrinho com barras laterais, dotadas de bicos dissipadores com válvulas reguladoras de pressão, com a finalidade de se obter lâmina de água constante e homogênea durante a aplicação. Após este período foi fornecida lâmina de água de, aproximadamente, $27 \mathrm{~mm}$ na áreasemdeficiência hídrica, e fornecida metade desta lâmina naárea com deficiência hídrica $(14 \mathrm{~mm})$.O turno de rega foi ajustado de acordo com a evapotranspiração da cultura, determinada por meio de tensiômetros localizados na área sem déficit hídrico, e cujas 
cápsulas porosas encontravam-se a $0,15 \mathrm{~m}$ de profundidade no solo. Foi considerada como condição de estresse, a tensão de água no solo acima de $200 \mathrm{mb}$, conforme descrito por Stone et al. (1986).

Foram efetuadas as avaliações da caracterização e do estudo fitossociológico da comunidade infestante ao final do ciclo reprodutivo do arroz.As avaliações foram feitas com olançamento aleatório de quadro metálico com dimensões de $0,5 \times 0,5 \mathrm{~m}$, com média de 60 lançamentos $\mathrm{ha}^{-1}$, em caminhamento em zigue-zague. As plantas foram contadas e identificadas segundo a família, gênero e espécie, de acordo com Lorenzi (1994). As partes aéreas das plantasdaninhas foram coletadas e separadas porespécie, determinando-se os valores de massa seca, obtidaapós a secagem em estufa com ventilação forçada de ar por 72 horas, a $70^{\circ} \mathrm{C}$, até atingir massa constante, pesadas em balança com precisão de $0,001 \mathrm{~g}$.

A partir da identificação, quantificação e pesagem das espécies presentes foram calculadas o número total de indivíduos (NI) de cada espécie, a densidade total das plantas (DT),a densidade relativa (DR) (Curtis and Mcintosh, 1950), a frequência (F) (Martins, 1978), a frequência relativa (FR) (Mueller-Dombois and Ellenberg, 1974), o peso total de cada espécie (PT) e o peso por planta (PP), em cada condição de irrigação.

\section{RESULTADOS E DISCUSSÃO}

Foram encontradas, ao final do ciclo reprodutivo, no ano de 2008, 13 espécies de plantas daninhas na cultura do arroz de terras altas, em ambas as condições de irrigação, sendo que algumas delas encontradas na condição sem estresse de seca não o foram na condição com estresse e vice-versa. Naquela primeira condição foram encontrados exemplares pertencentes anovefamílias botânicas (Tabela 2),destacando-se,em número de espécies presentes, as famílias Asteraceae, Euphorbiaceae, Poaceae e Rubiaceae, com 15,38\% da densidade relativa da família (DRF) cada. Já na condição com estresse de seca foram encontrados exemplares pertencentes a oito famílias botânicas (Tabela 3), destacando-se, em número de espécies presentes, as famílias Euphorbiaceae e Rubiaceae, com 23,08\% da DRFcada, seguido da família Poaceae, com 15,38\%.

Tabela 2. Distribuição de plantas daninhas por família, densidade relativa da família (DRF), nome científico e nome comum identificadas no tratamento sem estresse de seca, no ano de 2008, em GurupiTO.

\begin{tabular}{lcll}
\hline \multirow{2}{*}{ Famílias } & \multirow{2}{*}{ RDF (\%) } & \multicolumn{1}{c}{ Nome científico } & \multicolumn{1}{c}{ Espécies } \\
\cline { 3 - 4 } Asteraceae & 15,38 & $\begin{array}{l}\text { Acanthospermum hispidum } \\
\text { Emilia sonchifolia }\end{array}$ & $\begin{array}{l}\text { Carrapicho-de-carneiro } \\
\text { Falsa-serralha }\end{array}$ \\
\hline Convolvulaceae & 7,69 & Ipomoea aristolochiifolia & Corda-de-viola \\
\hline Euphorbiaceae & 15,38 & $\begin{array}{l}\text { Chamaesyce hyssopifolia } \\
\text { Euphorbia heterophylla }\end{array}$ & $\begin{array}{l}\text { Erva-andorinha } \\
\text { Leitero }\end{array}$ \\
\hline Lamiaceae & 7,69 & Marsypianthes chamaedrys & Hortelã-do-campo \\
\hline Malvaceae & 7,69 & Sida rhombifolia & Guanxuma \\
\hline Onagraceae & 7,69 & Ludwigia hyssopifolia & Cruz-de-malta \\
\hline Poaceae & 15,38 & $\begin{array}{l}\text { Cenchrus echinatus } \\
\text { Digitaria horizontalis }\end{array}$ & $\begin{array}{l}\text { Carrapicho, timbête } \\
\text { Capim-colchão }\end{array}$ \\
\hline Rubiaceae & 15,38 & $\begin{array}{l}\text { Spermacoce latifolia } \\
\text { Spermacoce verticillata }\end{array}$ & $\begin{array}{l}\text { Poaia-do-campo, erva-quente } \\
\text { Poaia-preta }\end{array}$ \\
\hline Solanaceae & 7,69 & Solanum sisymbriifolium & Joá-bravo \\
\hline
\end{tabular}


Tabela 3. Distribuição de plantas daninhas por família, densidade relativa da família (DRF), nome científico e nome comum identificadas no tratamento com estresse de seca, no ano de 2008, em GurupiTO.

\begin{tabular}{lcll}
\hline \multirow{2}{*}{ Famílias } & \multirow{2}{*}{ RDF $(\boldsymbol{\%})$} & \multicolumn{2}{c}{ Espécies } \\
\cline { 3 - 4 } & 12,5 & Nome científico/ Scientificname & Nome comum/ Common name \\
\hline Asteraceae & 12,5 & Ipomoea aristolochiifolia & Falsa-serralha \\
\hline Convolvulaceae & \multirow{2}{*}{ Corda-de-viola } \\
\hline Euphorbiaceae & 37,5 & $\begin{array}{l}\text { Chamaesyce hirta } \\
\text { Croton lobatus } \\
\text { Euphorbia heterophylla }\end{array}$ & $\begin{array}{l}\text { Quebra-pedra-rasteiro } \\
\text { Erva-de-rola, café-bravo } \\
\text { Leiteiro }\end{array}$ \\
\hline Fabaceae & 12,5 & Crotalaria juncea & Crotalária \\
\hline Malvaceae & 12,5 & Sida rhombifolia & Guanxuma \\
\hline Onagraceae & 12,5 & Ludwigia hyssopifolia & Cruz-de-malta \\
\hline Poaceae & 25,0 & $\begin{array}{l}\text { Cenchrus echinatus } \\
\text { Digitaria horizontalis }\end{array}$ & $\begin{array}{l}\text { Carrapicho, timbête } \\
\text { Capim-colchão }\end{array}$ \\
\hline \multirow{2}{*}{ Rubiaceae } & 37,5 & $\begin{array}{l}\text { Spermacoce latifolia } \\
\text { Spermacoce suaveolens } \\
\text { Spermacoce verticillata }\end{array}$ & $\begin{array}{l}\text { Poaia-do-campo, erva-quente } \\
\text { Poaia-botão } \\
\text { Poaia-preta }\end{array}$ \\
\hline
\end{tabular}

Considerando-se a densidade relativa das espécies na área sem estresse de seca,as espécies infestantes que mais se destacaram foram Digitaria horizontalis e Emilia sonchifolia, com 54,96 e
$19,08 \%$, respectivamente (Tabela 4). Essas espécies também foram destaque na condição com estresse, com um total de47,37 e 10,53\%, respectivamente (Tabela 5).

Tabela 4. Número de indivíduos (NI), densidade total (DT), densidade relativa da espécie (DRE), frequência (F) e frequência relativa (FR) sem estresse de seca no ano de 2008, em Gurupi - TO.

\begin{tabular}{|c|c|c|c|c|c|}
\hline Espécies & NI & TD $\left(\mathbf{p l ~ ~ m ^ { - 2 } )}\right.$ & RDE (\%) & $\mathbf{F}$ & RF (\%) \\
\hline Acanthospermum hispidum & 3 & 0,80 & 2,29 & 0,133 & 6,45 \\
\hline Cenchrus echinatus & 5 & 1,33 & 3,82 & 0,133 & 6,45 \\
\hline Chamaesyce hyssopifolia & 9 & 2,40 & 6,87 & 0,133 & 6,45 \\
\hline Digitaria horizontalis & 72 & 19,20 & 54,96 & 0,467 & 22,58 \\
\hline Emilia sonchifolia & 25 & 6,67 & 19,08 & 0,467 & 22,58 \\
\hline Euphorbia heterophylla & 4 & 1,07 & 3,05 & 0,133 & 6,45 \\
\hline Ipomoea aristolochiifolia & 1 & 0,27 & 0,76 & 0,067 & 3,23 \\
\hline Ludwigia hyssopifolia & 1 & 0,27 & 0,76 & 0,067 & 3,23 \\
\hline Marsypianthes chamaedrys & 3 & 0,80 & 2,29 & 0,133 & 6,45 \\
\hline Sida rhombifolia & 3 & 0,80 & 2,29 & 0,133 & 6,45 \\
\hline Solanum sisymbriifolium & 1 & 0,27 & 0,76 & 0,067 & 3,23 \\
\hline Spermacoce latifolia & 2 & 0,53 & 1,53 & 0,067 & 3,23 \\
\hline Spermacoce verticillata & 2 & 0,53 & 1,53 & 0,067 & 3,23 \\
\hline Total & 131 & 34,93 & 100,00 & 2,067 & 100,00 \\
\hline
\end{tabular}

Tabela 5. Número de indivíduos (NI), densidade total (DT), densidade relativada espécie (DRE), frequência (F) e frequência relativa (FR) sob estresse de seca no ano de 2008, em Gurupi - TO.

\begin{tabular}{lccccc}
\hline Espécies & $\mathrm{NI}$ & $\mathrm{TD}\left(\mathrm{pl} \mathrm{m}^{-2}\right)$ & $\mathrm{RDE}(\%)$ & $\mathrm{F}$ & $\mathrm{RF}(\%)$ \\
\hline Cenchrus echinatus & 4 & 1,07 & 5,26 & 0,067 & 4,00 \\
Chamaesyce hirta & 7 & 1,87 & 9,21 & 0,133 & 8,00 \\
Crotalaria juncea & 1 & 0,27 & 1,32 & 0,067 & 4,00 \\
Croton lobatus & 5 & 1,33 & 6,58 & 0,067 & 4,00
\end{tabular}




\begin{tabular}{lccccc} 
Digitaria horizontalis & 36 & 9,60 & 47,37 & 0,333 & 20,00 \\
Emilia sonchifolia & 8 & 2,13 & 10,53 & 0,267 & 16,00 \\
Euphorbia heterophylla & 2 & 0,53 & 2,63 & 0,067 & 4,00 \\
Ipomoea aristolochiifolia & 2 & 0,53 & 2,63 & 0,067 & 4,00 \\
Ludwigia hyssopifolia & 1 & 0,27 & 1,32 & 0,067 & 4,00 \\
Sida rhombifolia & 3 & 0,80 & 3,95 & 0,200 & 12,00 \\
Spermacoce latifolia & 1 & 0,27 & 1,32 & 0,067 & 4,00 \\
Spermacoce suaveolens & 5 & 1,33 & 6,58 & 0,067 & 4,00 \\
Spermacoce verticillata & 1 & 0,27 & 1,32 & 0,200 & 12,00 \\
\hline Total & $\mathbf{7 6}$ & $\mathbf{2 0 , 2 7}$ & $\mathbf{1 0 0 , 0 0}$ & $\mathbf{1 , 6 6 7}$ & $\mathbf{1 0 0 , 0 0}$ \\
\hline
\end{tabular}

$\mathrm{Na}$ condição sem estresse constatou-se maior incidência de plantas daninhas por área em comparação com a condição dedeficiência hídrica, devido a umacondição ambiental mais favorável tanto para o desenvolvimento da cultura quanto para o desenvolvimento da planta daninha.

As espécies Acanthospermum hispidum, Chamaesyce hyssopifolia, Marsypianthes chamaedrys e Solanum sisymbriifolium foram observadas na condição sem estresse, não tendo sido, porém, observadas na outra condição estudada. Já as espécies Chamaesyce hirta,Crotalaria juncea, Crotonlobatus e Spermacoce suaveolens foram encontradas na condição com estresse de seca, não sendo, porém, observadas na condição sem estresse. Supõe-se, então, que as primeiras espécies citadas, apesar de exercerem efeito competitivo sobre as plantas de arroz, seriam menos rústicas, apresentando menor capacidade adaptativa às condições estressantes de menor disponibilidade de água.

As matérias secas individuaismédias das plantas daninhas no ambiente com estresse de seca tenderam a ser mais reduzidas em relação ao ambiente sem estresse (Tabela 6). Tal fato já era esperado, sabendo-se que a deficiência hídrica leva, dentre outras consequiências, ao menor crescimento das plantas (Bota et al., 2004; Shinozaki e Yamaguchi-Shinozaki, 2007).

Tabela 6. Peso seco total (PT) e peso seco individual (PI) das plantas daninhas encontradas nas condições com e sem estresse de seca.

\begin{tabular}{lcccc}
\hline \multirow{2}{*}{ Espécies } & \multicolumn{2}{c}{ Sem estresse } & \multicolumn{2}{c}{ Com estresse } \\
\cline { 2 - 5 } & TW (g) & IW (g) & TW (g) & IW (g) \\
\hline Acanthospermum hispidum & 66,12 & 22,04 & - & - \\
Emilia sonchifolia & 76,19 & 3,05 & 21,81 & 2,73 \\
Ipomoea aristolochiifolia & 28,64 & 28,64 & 36,58 & 18,29 \\
Chamaesyce hyssopifolia & 10,22 & 1,14 & - & - \\
Chamaesyce hirta & - & - & 0,91 & 0,13 \\
Croton lobatus & - & - & 1,78 & 0,36 \\
Crotalaria juncea & - & - & 40,35 & 40,35 \\
Euphorbia heterophylla & 0,93 & 0,23 & 0,14 & 0,07 \\
Marsypianthes chamaedrys & 15,04 & 5,01 & - & - \\
Sida rhombifolia & 2,87 & 0,96 & 1,8 & 0,60 \\
Ludwigia hyssopifolia & 4,17 & 4,17 & 0,6 & 0,60 \\
Cenchrus echinatus & 18,71 & 3,74 & 17,6 & 4,40 \\
Digitaria horizontalis & 85,56 & 1,19 & 36,81 & 1,02 \\
Spermacoce latifolia & 2,19 & 1,10 & 0,74 & 0,74 \\
Spermacoce suaveolens & - & - & 2,09 & 0,42 \\
Spermacoce verticillata & 4,08 & 2,04 & 1,37 & 1,37 \\
Solanum sisymbriifolium & 28,59 & 28,59 & - & - \\
\hline Total & $\mathbf{3 4 3 , 3 1}$ & $\mathbf{1 0 1 , 8 9}$ & $\mathbf{1 6 2 , 5 8}$ & $\mathbf{7 1 , 0 7}$ \\
\hline
\end{tabular}


As espécies com maior biomassa individual no ambiente com irrigação normal (sem estresse) foram Ipomoea aristolochiifolia, Solanum sisymbriifoliume, Acanthospermum hispidum com 28,64; 28,59 e 22,04 gramas por planta, respectivamente. Entretanto, com exceção de $A$. hispidum, a qual apresentou três indivíduos, as outras duas espécies apresentaram somente um indivíduo cada, evidenciando serem estas, potencialmente, menos competitivas, nas condições da presente pesquisa, apesar de terem apresentado maior biomassa.

$\mathrm{Na}$ área com estresse de seca, destacaram-se, pela maior biomassa individual, as espécies Crotalaria juncea e Ipomoea aristolochiifolia, com 40,35 e 18,29 gramasde matéria seca por planta, respectivamente. Apesar dea espécie Digitaria horizontalis apresentar baixo valor de fitomassa seca por indivíduo, verificou-se maior densidade de plantas em ambas as condições de cultivo, ou seja, alto grau de infestação, evidenciando tratar-se de espécie daninha de grande importância em ambas às condições de cultivo local de arroz de terras altas.

Levantamentos acerca da flora daninha emergente e daconsequiente perda de produção agrícola são importantes em predições de manejo de lavouras, considerando-se que as relações custo/benefício determinam as ações necessárias. Estimativas de perdas de produtividade econômica das culturas, a partir de bancos de sementes de plantas daninhas e de taxas de emergência, ou do número de plantas estimadas por unidade de área, são úteis e deverão estimular o uso de levantamentos fitossociológicos de comunidades infestantes em áreas agrícolas (Voll etal., 2003; Carbonell et al., 2001).

É conveniente ressaltar que, apesar da presença de diversas espécies daninhas em ambas as condições de cultivo, o nível de infestação, em geral, apresentou-se relativamente baixo para a cultura do arroz de terras altas, quando comparados com outros levantamentos(Silva, 2006). Tal constatação poderia ser atribuída ao efeito residual do herbicida oxadiazon, aliado ao reduzido espaçamento entre as linhas de plantas de arroz, atenuando os efeitos competitivos entre planta daninha e planta cultivada em fase inicial de desenvolvimento.O desenvolvimento da cultura, e posterior sombreamento do solo, teria dificultado a germinação de sementes fotoblásticas positivas das espécies espontâneas presentes no banco de sementes. Pode-se cogitar, também, que a mesma quantidade de espécies encontradas em ambas as condições, poderia ter sido consequiência da pressão de seleção exercida pelo herbicida utilizado.

\section{CONCLUSÕES}

As espécies daninhas de maior destaque em ambas as condições de irrigação foram Digitaria horizontalis e Emilia sonchifolia, havendo tendência de diminuição nas suas densidades na condição de estresse de seca.

As variações nas composições florísticas infestantes entre ambas as condições de cultivo foram muito pequenas, havendo, porém, maior incidência de plantas daninhas por área no ambiente sem estresse de seca em comparação com a condição de deficiência hídrica.

Houve redução da fitomassa seca das plantas daninhas no ambiente comestresse de seca.

\section{AGRADECIMENTOS}

À EMBRAPA - ARROZ E FEIJÃO, por meio do Projeto Orygens.

\section{RESUMO}

O objetivo do trabalho foi avaliar a comunidade infestante e a massa seca na cultura do arroz de terras altas, sob duas condições de irrigação (com e sem estresse de seca). $O$ experimento foi instalado na Estação Experimental pertencente à Universidade Federal do Tocantins (UFT), Campus de Gurupi-TO. O levantamento da comunidade infestante foi feito ao final do ciclo reprodutivo das plantas de arroz, por método da amostragem, sendo as mesmas, coletadas para avaliar as massas secas. Dentre as famílias infestantes encontradas no experimento, constatou-se a ocorrência de menor número (8 famílias) na área com estresse de seca em relação à área sem estresse (9 famílias). O número de espécies encontradas foi $\mathrm{o}$ mesmo (13 espécies) em ambas as áreas, havendo variação, de acordo com o ambiente de cultivo. As espécies que mais se destacaram foram Digitaria horizontalis e Emiliasonchifolia para ambas as condições. As plantas infestantes, na condição de estresse de seca, tenderam a apresentar menor massa seca quando comparadas àquelas sob condição sem estresse por deficiência hídrica.

Palavras-chave: Estresse de seca, planta daninha, massa seca, Oryza sativa $\mathrm{L}$

\section{REFERÊNCIAS}

Bota, J.; Medrano, H.; Flexas, J. (2004), Is photosynthesis limited by decreased Rubisco activity and RuBP content under progressive water stress. New Phytologist, 62, 671-681. 
Carbonell, R.M.; Yanis, A.G.; Rubial, A.G.; Pereiro, G.A.; Sousa, J.G.; Victoria, F.C. (1998), Guía para el trabajo de campo en el manejo integrado de plagas del arroz. Cali: FLAR/CIAT, $55 \mathrm{p}$.

Concenço, G.; Ferreira, E.A.; Silva, A.A.; Ferreira, F.A.; Viana, R.G.; D'antonino, L.; Vargas, L.; Fialho, C.M.T. (2007),Uso da água em biótipos de azevém (Lolium multiflorum) em condição de competição. Planta Daninha, 25, 449-455.

Curtis, J.T. e Mcintosh, R.P. (1950), The interrelations of certain analytic and synthetic phytossociological characters. Ecology,31, 434455.

Erasmo, E.A.L.; Costa, N.V.; Pinheiro, L.L.A.; Silva, J.I.C.; Terra, M.A. Sarmento, R.A.; Cunha, A.M.; Garcia, S.L.R.(2003), Efeitos da densidade e dos períodos de convivência de Cyperus esculentus na cultura do arroz irrigado. Planta Daninha, 21, 381-386.

Lorenzi, H. (1994), Manual de identificação e controle de plantas daninhas: plantio direto e convencional. 4.Ed. Nova Odessa: Ed. Plantarium, 299 p.

Martins, F.R. Critérios para a avaliação de recursos naturais. (1978), In: Simpósio sobre a comunidade vegetal como unidade biológica, turística e econômica, 1978, São Paulo. Anais... Academia de Ciências do Estado de São Paulo, p. 136-149. (Publicação ACIESP, 15).

Mueller-Dombois, D. e Ellemberg, H. (1974), Aims and methods of vegetation ecology. New York: John Wiley \& Sons, 547p.

Nguyen, H.T.; Babu, R.C.; Blum, A. (1997), Breeding for drought resistance in rice: physiology and molecular genetics considerations. Crop Science, 37, 1426-1437.

Paulo, E.D.; Fujwara, M.; Nishida, T. (1990), Controle das plantas daninhas na cultura de alface transplantada com o herbicida oxadiazom. Bragantia, 49, 403-411.

Procópio, S.O.; Santos, J.B.; Silva, A.A.; Donagemma, G.K.; Mendonça, E.S. (2004), Ponto de murcha permanente de soja, feijão e plantas daninhas. Planta Daninha, 22,35-41.

Seagro, Secretaria da Agricultura, Pecuária e do Abastecimento, Condições Ambientais, Governo do Estado do Tocantins, Disponível em: http://www.to.gov.br/seagro/v_menu.php?id=603. Acesso em: 05/02/2007.

Silva, E.F. da; Silva, V.A.C.; Guimarães, J.F. R.; Moura, R. R. de. (2011), Divergência fenotípica entre genótipos de arroz de terras altas. Revista Brasileira de Ciências Agrárias, 6, 280-286.

Silva, M.R.M. Períodos de interferência das plantas daninhas na cultura do arroz de terras altas. Tese (Doutorado em Produção Vegetal) Universidade Estadual Paulista, Faculdade de Ciências Agrárias e Veterinárias, 2006.

Shinozaki, K. e Yamaguchi-Shinozaki, K. (2007), Gene networks involved in drought stress response and tolerance. Journal of Experimental Botany, 58, 221-227.

Stone, L.F.; Moreira, J.A.A.; Silva, S.C. da.(1986), Tensão da água no solo e produtividade do arroz.Goiânia:Embrapa - Cnpaf, 6p. (Circular Técnico 19).

Taiz, L. e Zeiger, E. (2009), Fisiologia Vegetal.4.Ed. Porto Alegre: Artimed, 819p.

Vidal, M.S.; Carvalho, J.M.F.C.; Meneses, C.H.S.G. (2005), Déficit Hídrico: Aspectos Morfofisiológicos.Campina Grande: Embrapa, 19p. (Documentos 142).

Voll, E.; Adegas, F.S.; Gazziero, D.L.P.; Brighenti, A.M.; Oliveira, M.C.N. de. (2003), Amostragem do banco de semente e flora emergente de plantas daninhas. Pesquisa Agropecuária Brasileira, 38, 211-218. 